\title{
Analysis and Revelation on Assessment Methods of Teaching Procedure in Overseas Universities
}

\author{
Haifeng Zhang ${ }^{1, a}$, Qingzhu Qi ${ }^{2}$ b* \\ ${ }^{1}$ Public Course Teaching Department, Tianjin College of Commerce, China \\ ${ }^{2}$ School of Management, Tianjin Polytechnic University, Xiqing District, Tianjin, China \\ a1707286010@qq.com, ${ }^{\text {b*5439112@qq.com }}$
}

Keywords: High Education; Course assessment; Procedure; Exam database;Teacher

\begin{abstract}
The current teaching assessing method of higher education in China has its drawbacks. Course evaluation gives higher priority to the final summarized examination rather than a formative exam which tests learning process. While the final exam takes more close-book examinations which focuses more on theory than practice. The application of open-style test and assessment on practice teaching is rarely used, which usually can not accurately reflect the real level of students and the assessment results cannot be objective and comprehensive. This paper proposes suggestions on methods of assessing students' learning based on process assessment by analyzing China's higher education assessing system and contrasting case study on assessing methods of both domestic and abroad.
\end{abstract}

\section{Introduction}

At present, teaching in China's higher education is basically still in the form of being examined by propositions from teachers. The assessing methods are relatively single and teaching assessment results is basically examined by a single exam. The content of the exam mostly falls on inspecting abilities of recitation and memorization of basic knowledge. However, these abilities are not the main teaching target in training students. This assessment method and the training target is a contradiction. As for assessment to the teachers, it has two flaws: the first is that the assessment factors is not reasonable, the second is that the assessment pays more attention to the form and lack of supervision to the process, especially lack of scientific teaching effectiveness system and the corresponding incentive and restraint mechanism. In addition, the main means to assess the learning effects for students is the obtaining of the credit. Under the credit system model, as long as the students achieve the standards of credit, they will be assessed as passed. Thus, to some extent, teaching assessment under the credit system model and its generated scores become the soul of the current teaching assessment system[1].

\section{The Analysis of Drawbacks of Current Higher Education Teaching Assessment Methods}

The Final Exam Model Cannot Reflect the Real Learning Level of Students Comprehensively and Accurately. The current teaching assessment system tends to emphasis more on results but ignoring the process. Teaching is a very complicated process, so that it is unfair to be judged by a single test. In existing curriculum assessment there is a fact that we called "five more, five less". They are: more close-book exams, less open-style exams; more written exams, less oral test, defense test and other methods; more summative exams, less comprehensive assessing methods which have various testing and teaching process; more with unique and standard answers, less examination questions with indefinite answers. More tests on theory, less examination focusing on practice abilities. As long as the students pass the exam of the course, then they can get the credits. The credit system which gives 
priority to summative exams decides the students' learning results by a single test. Because of impacts of random factors, a single test can not reflect the real level of students accurately and objectively.

The Content of the Exams Which Emphasize on Theory and Ignore Practice Turn Against Cultivating the Students' Comprehensive Quality and Ability. Application ability is important in assessing students' learning, but in the implementation process, the fact is that testing questions are dumb and boring and ignore assessment on practice. Practice courses takes a minor percent in the whole setting curriculum in many colleges, both teachers and students pay less attention to the practical courses. This does no help to the improvement of students' major learning; on the other hand, assessment which focuses on theory with less open-style questions and practical process is also harmful to the cultivation of students' integrative qualities.

Be Harmful to the Cultivation of Students' Creative Abilities and Autonomy Abilities. The current examination system of teaching determines that whether students can get credits by the final exam, while the content of final exams focus on theoretical knowledge rather than the understanding and application of knowledge. As a result, quit a lot of students pass the exam by reciting and memorizing the basic knowledge instead of giving a real thinking of it, not to mention the understanding and application of knowledge. All of this is harmful for the cultivation of students' creative abilities and autonomy abilities. Furthermore, in current examination system of teaching, when the teaching content and the final exam questions overlap more and fall in a narrow range, it is not helpful to cultivate the interest to this course. While the teaching content and the final exam questions overlap less, it will reduce the students' enthusiasm in classroom learning.

Affect Both Teachers' and Students' Enthusiasm. To some extent, a distempered teaching assessing system and inadequate teaching assessing mechanisms have a bad effect on teachers' teaching as well as students' learning enthusiasm. For teachers, the assessment by the exam is just a means to grade the students; for students, assessment is just t a step to get a score which serve them to get a diploma for graduation; the administrative office in charge of teaching regard the assessment only as a means of testing which help them to decide the students' upgrading and graduation and pay less attention to promotion on teaching, learning and administration. As result, the current examination system of teaching easily tends to focus on "teaching only aiming at scores, testing only aiming at learning, learning only aiming at credentials", which cannot effectively motivate the enthusiasm of both teaching and learning. All of this lead to the current view "high score but low in abilities" [2]. To some extent, it has a bad effect on teaching effectiveness and the cultivation on quality of intellectuals.

\section{The Methods and Enlightenment of Teaching Examination in Overseas Universities}

In foreign countries, professors have the power to design teaching methods, which attach great importance to the learning process management and pay attention to the performance in courses, including tests, examinations, evaluations of group discussions, assignments and classroom performance. The final grade is an integration of curriculum learning process rather than one test.

In Brigham Young University-Provo, all course grades are evaluated in the form of score points, which requires the teacher publishing the calculation method of score points in the syllabus in advance. For example, the score points of "accounting principles" includes: the basic content of the online test (180 points); assignments (70 points); classroom group test (110 points); the mid-term exam 1 (100 points); mid-term exam 2 (160 points); mid-term exam 3 (130 points) and a final exam (250 points). The corresponding levels of the scores are A (930 - 1000), A- (870 - 929), B+ (820 - 869), B (730 - 819), B(620 - 729), C+ (500 - 619) and C+ (below 500).Shown in the following Table 1. 
Table 1 Score Pattern of Brigham Young University's Accounting Principles Teaching Syllabus

\begin{tabular}{|c|c|c|}
\hline Patterns & Scores & $\%$ \\
\hline Basic online test $(21,3$ lowest grade will be the lowest level ) & 180 & \multirow{6}{*}{$75 \%$} \\
\hline Assignment (4) & 70 & \\
\hline Classroom group test $(12,1$ lowest grade will be the lowest level ) & 110 & \\
\hline Mid-term exam 1 & 100 & \\
\hline Mid-term exam 2 & 160 & \\
\hline Mid-term exam 3 & 130 & \\
\hline Final exam & 250 & $25 \%$ \\
\hline Total score & 1000 & $100 \%$ \\
\hline
\end{tabular}

The three mid-term exams and a comprehensive final exam involve the basic knowledge and all group discussions in class. Exams, which are organized by the testing center, are in form of multiple-choice. The mid-term exams time last 4 hours, about 150 minutes to complete; the final exam time lasts 5 hours, probably 180 minutes to complete.

After a detailed analysis of the Teaching Syllabus of "accounting principles", we can find that the content is very rich, including teacher's information (Office time, class time and place), specific course teaching objectives, books and other teaching materials, main task, basic content of learning, the form of class, assignments, grading and detailed course plan[3].

Teachers will give the students detailed course schedules at the beginning of term, which are specific to the month, date, the curriculum content, time of test and examination and time to submit homework. The students can preview, review and prepare group discussion according to their own situation after getting the curriculum plan. The teaching content of Brigham Young University-Provo is very rich, aiming to cultivate the practical ability of students, rather than copy textbook.

\section{Comparative Analysis of Domestic and Foreign Teaching Assessment mode}

As can be seen from the above examples, Brigham Young University impose strict scoring system for students, as well as a rich variety of evaluation methods and teaching process control concepts. The final exam of Accounting Principles accounts for $25 \%$ of total evaluation results and various tests, discussion and homework in the process of learning accounts for $75 \%$. Through comparative analysis, we can draw the following conclusions:

Comparative Analysis of Assessment Purpose. The assessment purpose of the course is reflected in the purpose of the creation of the course, which is the prerequisite for the implementation of the curriculum assessment. If there is no specific purpose, the curriculum assessment will not only lose its direction, but also there will be no basis to support it. Assessment purpose for most of the foreign management course is specific and clear, which mainly evaluates whether the students master the basic skills, whether they have the spirit of transcendence, critical thinking and creative thinking, and that is consistent with comprehensive development concept on the management. Compared with foreign assessment objectives, Chinese undergraduate management study is more general and not specific enough, which is difficult to implement into the curriculum objectives and also have not formed a clear direction. Therefore, it is difficult to produce incentive effect to the students and to guide students toward future career goals. 
Comparative Analysis of the Emphasis on the Assessment Feedback. In general, the assessment can make students give feedback to teachers' teaching effect and quality, and also can provide a reference for teachers to find teaching problems, so that they can make adjustments and improvements timely. The abroad course assessment feedback goes after the following practice: Teachers make strict attendance records of the students, and ask students to turn in written assignments on a regular basis; they organize classroom quizes irregularly or regularly and analyzing students' written assignments to reflect on their own teaching as a basis for continuous improvement of teaching content and teaching methods. In China, teachers rarely quiz or make strict attendance supervision.

Comparative Analysis on the Scope of Assessment. Foreign teaching assessment has a wide scope and the exam answers need to be drawn throughout the overview of the full text and Synthesis. In order to achieve good results, the students usually must pay attention to strengthen their knowledge reserve and broaden knowledge structure as far as possible; otherwise, they cannot get good achievement only by cramming before the exam. In addition to the course materials, lecture notes, the assessment scope often involves extra-curricular knowledge, social practice and innovations. At the same time, the set of the course examination is more scientific, focusing on the assessment of students' ability to analyze problems and solve problems. In general, examinations are given priority subjective questions with flexible answers and many problems require students to think and explore in many different ways. In contrast, the content of Chinese examinations is confined to the basic theories in the textbooks and influenced by the standardized examination methods, so there are more objective questions such as filling blanks, judgment, multiple choice questions, short answer questions, terms explanation and less questions which need Comprehensive thinking, analysis, proving and application. The standardized questions have the only answers, leaving narrow space for the imagination of the students. The students only need to "transmit" from their memory rather than thinking about that[4].

Comparative Analysis on Assessment Methods. Assessment methods mainly refers to in what form the assessment may take. Whether it is scientific is directly related to the curriculum assessment results, thereby affecting the effectiveness of teaching. Foreign curriculum examination forms mainly include the mid-term examinations, usual grades (including quizzes, homework and class participation, term paper, etc.) and final exams. Teachers can select the appropriate forms of assessment according to the teaching schedule and requirements. In addition, foreign students are more inclined to the courses with relatively more examinations in the form of quizzes, tests and papers throughout the whole semester. Exam courses are frequent with not only the routine midterms and final exams, but also a higher frequency of classroom tests, the results of which are part of the total score. At the same time, the choice of the ways of assessment can mainly take maximizing the students' real level as a standard. Teachers will allow students to bring a formula or books for an open-book exam, or give students commonly used theoretical comments, so that the students will put all attention to the questions analysis and application of the theories. China's course assessment methods are relatively simple, mainly focusing on memory assessment of objective knowledge through the paper tests such as the basic concepts and principles of the theory, which neglects examining other capabilities.

Comparative Analysis on the Rationality of Performance Assessment. Performance assessment mainly refers to deciding which way to assess student learning results, which is not only important means to urge the comprehensive and systematic study of the basic theories, basic knowledge and basic skills, but also the important part to check the quality of student learning and teaching effectiveness. Foreign college curriculum assessment results mainly consist of the usual grades, midterm exams and final exam scores. Performance evaluation is mainly determined by the teachers according to students' performance at ordinary time like attendance and participation in class discussions, social practice participation feedback, term paper, all quiz and many other contents. Among them, the usual grades account for a larger proportion and the performance evaluation focuses on examining students' ability and level, seeking to assess the accuracy and objectivity. The usual grades in most of China's college only accounts for about $20 \%$, and are given more casually. The student's results almost depend on the 
final exams. Most of the students "cram" for the exams and even cheat to deal with the tests, which leads to the lack of accuracy and objectivity.

\section{Revelation}

The successful experience of foreign education evaluation is worth using for reference and absorption in strengthening the assessment of teaching of undergraduate management disciplines. Since the experience is mainly in line with the local situation, so it is not totally suitable for Chinese reality. We should take it critically[5].

First, strengthen students' assessment in the learning process and take it as feedback to improve the teaching. Teachers should strengthen the evaluation of students' daily performance, increase routine examination proportion in the total grade, make sure the ordinary tests and practice should be no less than a certain number. At the same time, get feedback from the routine examination to change teaching methods, contents and teaching process.

Second, enrich assessment patterns and develop the content of examination. Based on subject characteristics, assessment mode should combine ordinary tests and final exam. Teachers can appropriately increase group discussion, class assignments, case analysis, debate, small paper and other forms as an important part of students' final evaluation system. These measures can truly reflect the students' learning effect about their professional knowledge and skills.

Third, promote the diversification of examination form. Apart from the closed-book examination, more ways like open-book exam, half open and half close examination, class participation, term paper, etc. should be invited. And we can also establish test library on the internet so we can test students' subject fundamental knowledge at any time. The diversification of examination form can improve students' comprehensive knowledge and analysis ability to solve problems.

\section{Acknowledgements}

This article is part of the results funded by Research Project of Tianjin Undergraduate Teaching Quality and Teaching Reform (The Reform and Practice of Teaching Evaluation Modes for Management Subject Based on Process Control Principle. No: C05-1102)

\section{References}

[1] Zhongying Zhou and Meijun Ma, Reflections of Teaching Assessment In Credit system, Economic Research Guide, vol.6(2011), p. 286-287.

[2] Yang Yuehu, Qi Qingzhu. The Weaknesses and Suggestions of Current Chinese Management Subject Teaching Assessment [J].International Conference of Education Reform and Innovation, 12 (2012),p. 99-103.

[3] Zhang Ting. Acadamic Standard of Bachelor Degree in United States; A Case Study of Brigham Young University [D] College of Teacher Education of Zhejiang Normal University,2010.

[4] Zhang Ting, Academic Standard of Bachelor Degree in United States; A Case Study of Brigham Young University, College of Education, Zhejiang Normal University, 2010.

[5] Qingyan Jia and Juxiang Zhang, Research of Investigation and Countermeasure on College English Assessment Mode, Journal of Liaoning University of Technology, vol.6(2011), p.110-111. 